\title{
Chronic Spontaneous Urticaria: the Emerging Role of Coagulation
}

\author{
Angelo V. Marzano • Alberto Tedeschi • \\ Claudia Menicanti • Riccardo Asero • Carlo Crosti • \\ Massimo Cugno
}

Published online: 3 February 2013

(C) Springer Science+Business Media New York 2013

\begin{abstract}
Chronic urticaria (CU) is a cutaneous disease characterized by the recurrent eruption of short-lived wheals for at least six weeks. The wheals, which are surface swelling of the dermis accompanied by itching, may be elicited by different stimuli, or occur spontaneously. The pathogenesis of spontaneous CU has long remained a mystery, with food allergy, intolerance to food additives and chronic infections having been indicated as the main causes of the disease. The demonstration of histamine releasing autoantibodies in the serum of $\mathrm{CU}$ patients led to consider it of autoimmune origin in about $45 \%$ of cases, this condition being "idiopathic" in the remaining $55 \%$. We recently evaluated the possible involvement of blood coagulation in its pathophysiology by measuring in $\mathrm{CU}$ patients the plasma levels of prothrombin fragment $\mathrm{F} 1+2$, a polypeptide released into the circulation during the activation of prothrombin to thrombin, and D-dimer, a marker of fibrin lysis. Interestingly, both $\mathrm{F} 1+2$ and D-dimer plasma levels
\end{abstract}

A. V. Marzano $(\varangle) \cdot$ C. Menicanti $\cdot$ C. Crosti

Unità Operativa di Dermatologia, Fondazione IRCCS Ca' Granda, Ospedale Maggiore Policlinico, Dipartimento di Fisiopatologia

Medico-Chirurgica e dei Trapianti, Università degli Studi di

Milano, Via Pace, 9,

20122 Milano, Italy

e-mail: angelovalerio.marzano@policlinico.mi.it

A. Tedeschi

Unità Operativa di Allergologia e Immunologia Clinica, Fondazione IRCCS Cà Granda, Ospedale Maggiore Policlinico, Milano, Italy

R. Asero

Ambulatorio di Allergologia, Clinica San Carlo, Paderno

Dugnano, Milano, Italy

\section{Cugno}

Medicina Interna, Dipartimento di Fisiopatologia

Medico-Chirurgica e dei Trapianti, Università degli Studi di

Milano, Fondazione IRCCS Ca' Granda, Ospedale Maggiore

Policlinico, Milano, Italy were extremely high during the acute phase of disease, but were completely normal after remission, paralleling urticaria severity. It is noteworthy that thrombin causes an increase in vascular permeability, thus amplifying the $\mathrm{CU}$ inflammatory network. Moreover, immunohistochemical studies showed expression of tissue factor, the main initiator of coagulation, in CU skin lesions, and co-localization experiments demonstrated that tissue factor is expressed by eosinophils in the inflammatory infiltrate. All these findings support that coagulation activation contributes in the pathophysiology of spontaneous CU, and provide the rationale for using also anticoagulant and antifibrinolytic agents to treat it.

Keywords Chronic urticaria $\cdot$ Blood coagulation · Thrombin $\cdot$ D-dimer $\cdot$ Ciclosporin

\section{Introduction}

Chronic urticaria (CU) is a skin disorder characterized by the recurrent eruption of short-lived wheals accompanied by redness and itching for at least 6 weeks [1]. The wheals are surface swellings of the dermis that are usually pale in the centre with a surrounding red flare when they erupt, and become pink when they mature (Fig. 1); they are frequently accompanied by itching and resolve in a period of hours without leaving any mark [2]. The wheals can be associated with deeper swelling of the dermis and subcutaneous and submucosal tissues, which is called angioedema. $\mathrm{CU}$ is a rather frequent disease with an estimated prevalence of 0.5 $1 \%[3,4]$; it may appear at any age, although it occurs more frequently in adults, affects more women than men $[2,3]$ (female/male ratio: $2 / 1$ ), and is characterized by a familiar pattern [4]. CU has a heavy impact on the quality of life; in fact, health status scores in patients with $\mathrm{CU}$ are comparable to those reported from patients with coronary artery disease, 
Fig. 1 Chronic spontaneous urticaria in three different patients: giant wheals on the back $(A)$, widespread wheals on the legs $(B)$ and large wheals on the right side of the trunk $(C)$
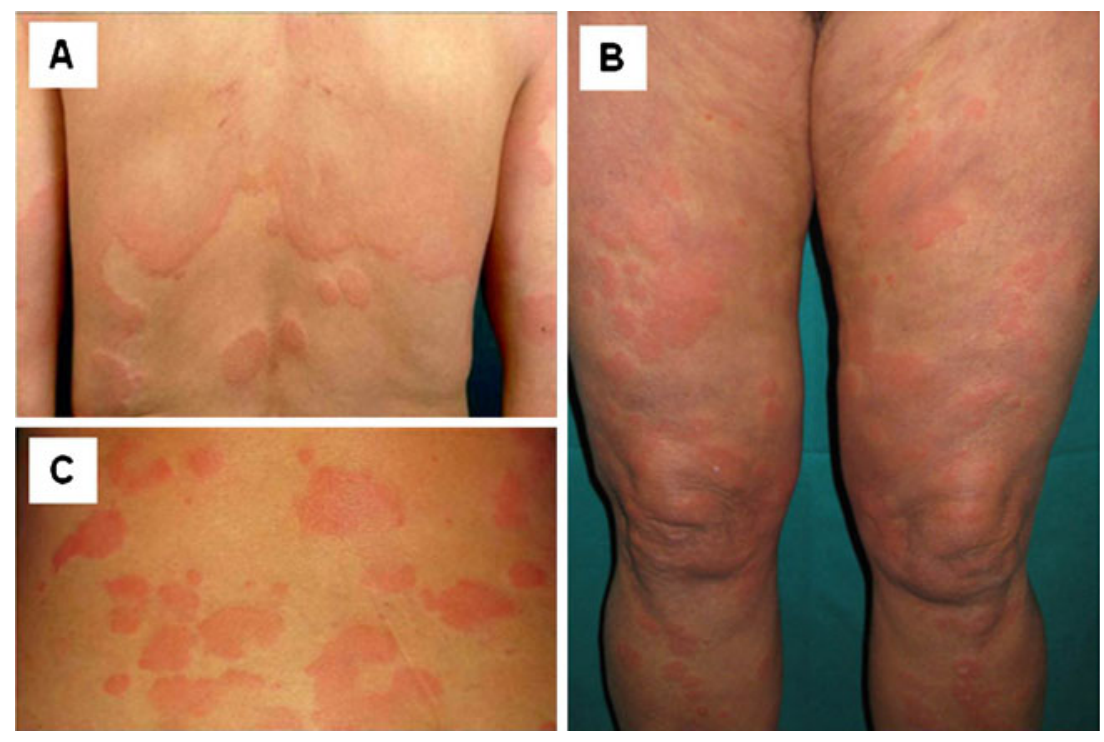

particularly in terms of work performance, sleep disruption, emotional reactions and social interactions [5]. Classification of urticaria distinguishes between subtypes in which eliciting factors are recognizable (including physical urticaria and forms such as aquagenic, cholinergic, contact and exercise-induced urticaria), and the subtype of spontaneous urticaria in which the wheals are not triggered by eliciting factors and is subdivided in the acute and chronic form based on its duration. In the present review, we will consider only chronic spontaneous urticaria (referring to it simply as $\mathrm{CU}$ in the text), focusing on the emerging role of coagulation activation in its complex pathophysiology $[6 \bullet]$.

\section{Etiology and Pathogenesis}

The pathogenesis of CU has long remained a mystery. The pathogenic mechanisms of $\mathrm{CU}$ have been elucidated over the last 20 years. Various factors have been suggested as causes of the disease, including emotional disorders [7, 8], food allergy, intolerance to food additives [9], and chronic infections such as Helicobacter pylori [10]. More recently, an autoimmune origin of $\mathrm{CU}$ has been supported by experimental and clinical findings [1] in approximately $45 \%$ of patients; in the remaining $55 \%$, the etiology is unknown and the condition remains 'idiopathic' [11]. In a variable proportion of patients with active disease (30-60\%), the intradermal injection of autologous serum (autologous serum skin test, ASST) causes a wheal-and-flare reaction, and serum from some $\mathrm{CU}$ patients induces histamine release from cultured basophils of healthy subjects. Both phenomena have been attributed to circulating IgG antibodies specific for the high-affinity IgE receptor on mast cells or for $\operatorname{IgE}[12-14]$. The IgG antibodies belong to subclasses 1 or 3
[15], and activate the classical complement cascade [16, 17]. Other autoantibodies may also contribute to CU: autoantibodies against $\mathrm{CD} 23$ (the low-affinity IgE receptor) have been demonstrated in $65 \%$ of patients with CU [18], and can indirectly cause mast cell degranulation in vitro as a result of the release of the major basic protein by eosinophils. The quite frequent association of $\mathrm{CU}$ with antithyroid antibodies [19-21], which are markers of autoimmunity [22], further supports the autoimmune nature of the disease. According to Altrichter et al. [23], IgE autoantibodies against thyroid peroxidase, which have been found in a subgroup of patients with chronic spontaneous urticaria, can cause mast cell degranulation, and thus represent a novel pathway of urticaria induction. The importance of this mechanism is supported by the efficacy of the anti-IgE monoclonal antibody omalizumab in a subset of $\mathrm{CU}$ patients with circulating anti-thyroid peroxidase autoantibodies refractory to conventional treatments [24]. In addition to autoantibodies, other histamine-releasing factors can contribute to mast cell activation in $\mathrm{CU}$. Most sera from CU patients either ASST-positive or ASST-negative were shown to induce in vitro degranulation of mast cell lines expressing or lacking the IgE receptor (LAD2 and HMC-1, respectively). Furthermore, IgG-depleted CU sera maintained the capacity of inducing mast cell degranulation, indicating that in $\mathrm{CU}$ mast cell degranulation can occur also by an IgE- and IgGindependent mechanism [25•]. The wheals of CU are due to the activation of dermal mast cells that secrete preformed mediators, including histamine (the main cause of pruritus), proteases, interleukin-1 and tumor necrosis factor- $\alpha$ [2]; high plasma levels of C-reactive protein, which is a wellknown acute phase reactant, and matrix metalloproteinases 2 and 9 (MMP-2 and MMP-9) [26, 27, 28•] contribute to the inflammatory state. MMP-9 is a zinc and calcium-dependent enzyme that contributes to inflammatory responses and 
subsequent tissue remodelling and repair [29]. MMP-9 also seems to be involved in a variety of pathological processes occurring during the course of autoimmune diseases such as systemic lupus erythematosus and rheumatoid arthritis [30], as well as autoinflammatory skin disorders such as pyoderma gangrenosum [31]. The importance of inflammation in $\mathrm{CU}$ is supported by the correlation between disease activity and plasma C-reactive protein and MMP-9 levels [28•].

\section{Role of Coagulation}

One of the additional mechanisms involved in the pathogenesis of $\mathrm{CU}$ is the activation of coagulation. We observed that positive autologous skin test rises up from 50 to $80 \%$ if autologous-citrated plasma instead of autologous serum is injected [32], and that CU patients show elevated plasma levels of prothrombin fragment $\mathrm{F} 1+2$, a polypeptide of about $34 \mathrm{kD}$ that is released into the circulation during the activation of prothrombin to thrombin by activated factor $\mathrm{X}$ (FXa) [32]. Interestingly, F1+2 plasma levels were found to be related to urticaria severity at the time plasma was collected [32]. The abovementioned findings may suggest that $\mathrm{CU}$ is associated with the generation of thrombin, and that the severity of the disease is paralleled by the amount of thrombin generated. Thrombin is a serine protease involved in hemostasis as well as in vessel wound healing, revascularization, and tissue remodeling [33]. It is of note for the pathophysiology of $\mathrm{CU}$ that thrombin is able to cause a relevant increase in vascular permeability $[34,35]$ and to activate mast cells, triggering their degranulation $[36,37]$. In subsequent studies, we find that $\mathrm{CU}$ patients show an activation of the coagulation cascade triggered by tissue factor (TF), which is a initiator of the extrinsic coagulation pathway [38]; moreover, in patients with severe disease, the coagulation activation can be so pronounced as to produce an elevation of plasma levels of D-dimer, the last being regarded as a sign of fibrinolysis [39]. Both F1+2 and Ddimer plasma levels prove to be extremely high during an acute phase of severe $\mathrm{CU}$, but are completely normal after remission [39]. In another study [38], immunohistochemical experiments show TF expression in skin specimens from $\mathrm{CU}$ patients. Recently, we demonstrated that TF is expressed by eosinophils present in the inflammatory infiltrate of CU skin lesions [40••]. The nature of the TFexpressing cells is revealed by performing double-staining studies that show co-localization of TF and eosinophil cationic protein, a classic cell marker of the eosinophil. These data highlight the importance of eosinophils in $\mathrm{CU}$ as a source of TF, in keeping with studies showing that eosinophils store TF and rapidly transfer it to the cell membrane during activation [41]. The strong expression of $\mathrm{TF}$ in $\mathrm{CU}$ lesional skin may be due to eosinophil activation, even if patients with $\mathrm{CU}$ virtually never show peripheral eosinophilia, probably because TF specifically facilitates the early transendothelial migration of the eosinophils [41]. The activation of the TF pathway of coagulation results in the generation of thrombin that, in experimental models, has been shown to induce edema through an increase in vascular permeability [34] by a direct effect on endothelial cells [42], and indirectly by a thrombin-related release of inflammatory mediators. Most effects of thrombin are probably histaminemediated (and hence mast cell-mediated), as they have been reported to be reduced by anti-histamines and mast cell granule depletion in animal models [39]. Furthermore, thrombin triggers mast cell degranulation [37], and may activate protease activated receptor- 1 on mast cells [35] in animal models. The activation of blood coagulation in patients with $\mathrm{CU}$ has been recently confirmed by other independent researchers [43-46], and thus can be added to the mechanisms involved in CU. In particular, Wang et al. [43] found elevated plasma levels of FVIIa (marker of the activation of the TF pathway), thrombin-antithrombin complex (marker of thrombin generation) and D-dimer (marker of fibrin degradation), which were correlated to each other in CU patients. Thrombin-antithrombin complex and Ddimer plasma levels were also found increased in CU by Fujii et al. [44]. Khalaf et al. [45] confirmed high levels of $\mathrm{F} 1+2$ during active $\mathrm{CU}$ and a significant decrease during remission. Finally, by means of clot waveform analysis and measuring the levels of coagulation factors and markers of activated coagulation, Takeda et al. observed that increased coagulation potential is closely associated with the symptoms of CU [46]. The TF-mediated coagulation pathway may also be involved in bullous pemphigoid (BP), which is the main autoimmune bullous skin disease characterized by the formation of blisters on normal or erythematous skin, and rarely on mucous membranes, as a result of the interaction of autoantibodies with two hemidesmosomal antigens (BP180 and BP230), followed by complement activation and leukocyte infiltration [47]. In BP, the involvement of coagulation is present both at systemic level, as supported by the fact that both the plasma and blister fluid of our BP patients displays significantly higher levels of D-dimer and $\mathrm{F} 1+2$ than normal plasmas, and at local level as demonstrated by the strong TF immunohistochemical expression in BP lesional skin [48-50]. We also evaluated the possible involvement of coagulation activation in a number of other inflammatory skin diseases; atopic dermatitis, a chronically relapsing immune-mediated inflammatory skin disease, also involves the local and systemic activation of coagulation, whereas in psoriasis, a erythematous-squamous inflammatory immune-mediated skin disorder, the activation of coagulation seems to be mainly systemic. In fact, we failed to disclose TF expression in lesional skin of patients with psoriasis. The activation of coagulation has also been 
suggested an additional pathomechanism in dermatitis herpetiformis, a chronic-relapsing autoimmune skin disease associated with gluten sensitivity and celiac disease, but its precise role has not yet been defined [51]. Taken together, these data provide the rationale for controlled clinical trials aimed at evaluating the usefulness of anticoagulant treatment in autoimmune skin disorders to counteract the local and systemic effects of coagulation activation [52].

\section{Clinical and Therapeutical Implications}

CU patients show an increase in the plasma markers of thrombin generation and fibrinolysis during severe disease exacerbations $[39,53 \bullet \bullet$. Moreover, the involvement of intrinsic coagulation factors may contribute in vivo to the generation of fibrin by even small amounts of thrombin $[44,46]$. The activation of coagulation and fibrinolysis decreases until complete normalization during the remission of CU [39]. However, to the best of our knowledge, it has never been reported that the hypercoagulable state seen in $\mathrm{CU}$ is associated with an increased risk of thrombosis. On the contrary, there are a number of reports of cardiovascular events (particularly myocardial infarction) occurring during episodes of acute urticaria [54-57]. Various pathomechanisms have been hypothesized to link urticaria and the cardiac events, including coagulation involvement, coronary artery spasm and/or atheromatous plaque erosion or rupture induced by inflammatory mediators. Whether the activation of coagulation and fibrinolysis in $\mathrm{CU}$ is pathophysiologically relevant or simply acts as an amplification system has still to be defined, but the fact that it parallels the disease activity has provided a rationale for evaluating anticoagulant and antifibrinolytic therapy in these patients. Heparin is an anticoagulant that potentiates the effect of antithrombin, the plasma protein that binds irreversibly to some serine protease enzymes (mainly factor Xa and thrombin) and blocks their activity. Isolated reports indicate that heparin can be effective in the treatment of CU $[58,59]$. Meyer-De Schmid and Neuman [58] observed persistent remission in four CU patients (complete in three and partial in one) treated with intravenous unfractioned heparin at a dose of 50-100 $\mathrm{mg}$ twice a day, corresponding to 5,000-10,000 U, and Chua and Gibbs [59] described complete remission in a CU patient refractory to antihistamine and immunosuppressive treatment during administration of subcutaneous unfractioned heparin $(5,000 \mathrm{U}$ twice a day), followed by a relapse when heparin was discontinued. Moreover, a small but double-blind, placebo-controlled trial found that the oral anticoagulant warfarin improved clinical symptoms in six out of eight patients with CU unresponsive to antihistamines [60], and in a recent uncontrolled study, Mahesh et al. [61] obtained remission with warfarin at a therapeutic dose in four out of five $\mathrm{CU}$ patients (complete in two and partial in two). The antifibrinolytic agent tranexamic acid is effective in patients with idiopathic angioedema or angioedema due to C1-inhibitor deficiency [62], a disorder characterized by activation of activation and fibrinolysis [63, 64], and has been proposed also for the treatment of CU. A good clinical response was reported in an anecdotal case [65], but this was not confirmed in a controlled study [66]. Asero et al. have recently found that patients with severe $\mathrm{CU}$ unresponsive to antihistamines and exhibiting high levels of D-dimer may benefit from combined treatment with low molecular weight heparin and tranexamic acid [67]. Taken together, these findings indicate the relevance of coagulation cascade activation in $\mathrm{CU}$. Blood coagulation, besides the anticoagulant agents, may be affected by ciclosporin, which has proven to be highly effective in the treatment of H1-antihistamine resistant $\mathrm{CU}[6 \cdot, 68-70,71 \bullet, 72,73]$. Ciclosporin is an immunosuppressive drug widely used to prevent the rejection of a transplanted organ and to treat diseases of autoimmune origin [74]. It was demonstrated that ciclosporin inhibits the TF activation that occurs in monocytes of cardiac transplant recipients [75]; these findings, which are also supported by in vitro experiments [76], may contribute to explain the successful use of ciclosporin A in cardiac transplant medicine. Thus, our future studies will be aimed at evaluating possible counteracting effects of ciclosporin A on TF-mediated coagulation activation occurring in $\mathrm{CU}$ patients.

Disclosures The authors report no potential conflicts of interest relevant to this article.

\section{References}

Papers of particular interest, published recently, have been highlighted as

- Of importance

-. Of major importance

1. Greaves M. Chronic urticaria. J Allergy Clin Immunol. 2000;105:664-72.

2. Grattan CE, Sabroe RA, Greaves MW. Chronic urticaria. J Am Acad Dermatol. 2002;46:645-57.

3. Greaves MW, Tan KT. Chronic urticaria: recent advances. Clin Rev Allergy Immunol. 2007;33:134-43.

4. Gaig P, Olona M, Munoz Lejarazu D, Caballero MT, Dominguez FJ, Echechipia S. Epidemiology of urticaria in Spain. J Investig Allergol Clin Immunol. 2004;14:214-20.

5. O'Donnell BF, Lawlor F, Simpson J, Morgan M, Greaves MW. The impact of chronic urticaria on the quality of life. $\mathrm{Br} \mathrm{J}$ Dermatol. 1997;136:197-201.

6. - Zuberbier T, Asero R, Bindslev-Jensen C, et al. EAACI/ GA2LEN/EDF/WAO guideline: definition, classification and diagnosis of urticaria. Allergy. 2009;64:1417-26. 
7. Shoemaker R. A search for the affective determinants of chronic urticaria. Psychosomatics. 1963;4:125-32.

8. Rees L. An etiological study of chronic urticaria and angioneurotic oedema. J Psychosom Res. 1957;2:172.

9. Michaelsson G, Juhlin L. Urticaria induced by preservatives and dye additives in food and drugs. Br J Dermatol. 1973;88:525-32.

10. Greaves MW. Chronic idiopathic urticaria and $\mathrm{H}$ pylori: not directly causative but could there be a link? ACI Int. 2001;13:23-6.

11. Kaplan AP, Greaves M. Pathogenesis of chronic urticaria. Clin Exp Allergy. 2009;39:777-87.

12. Grattan CE, Wallington TB, Warin RP, Kennedy CT, Bradfield JW. A serological mediator in chronic idiopathic urticaria: a clinical, immunological and histological evaluation. Br J Dermatol. 1986;114:583-90.

13. Gruber BL, Baeza ML, Marchese MJ, Agnello V, Kaplan AP. Prevalence and functional role of anti-IgE autoantibodies in urticarial syndromes. J Invest Dermatol. 1988;90:213-7.

14. Hide M, Francis DM, Grattan CEH, Hakimi J, Kochan JP, Greaves MW. Autoantibodies against the high affinity $\operatorname{IgE}$ receptor as a cause of histamine release in chronic urticaria. N Eng J Med. 1993;328:1599-04.

15. Soundararajan S, Kikuchi Y, Joseph K, Kaplan AP. Functional assessment of pathogenic IgG subclasses in chronic autoimmune urticaria. J Allergy Clin Immunol. 2005;115:815-21.

16. Ferrer M, Nakazawa K, Kaplan AP. Complement dependence of histamine release in chronic urticaria. J Allergy Clin Immunol. 1999;104:169-72.

17. Kikuchi Y, Kaplan A. A role for C5a in augmenting IgGdependent histamine release from basophils in chronic urticaria. $\mathrm{J}$ Allergy Clin Immunol. 2002;109:114-8.

18. Puccetti A, Bason C, Simeoni S, et al. In chronic idiopathic urticaria autoantibodies against $\mathrm{Fc}$ epsilonRII/CD23 induce histamine release via eosinophil activation. Clin Exp Allergy. 2005;35:1599-607.

19. Leznoff A, Sussman GL. Syndrome of idiopathic CU and angioedema with thyroid autoimmunity: a study of 90 patients. J Allergy Clin Immunol. 1989;84:66-71.

20. Turktas I, Gokcora N, Demirsoy S. The association of chronic urticaria and angioedema with autoimmune thyroiditis. Int J Dermatol. 1997;36:187-90.

21. O’Donnell BF, Francis DM, Swana GT, Seed PT, Kobza Black A, Greaves MW. Thyroid autoimmunity in chronic urticaria. Br J Dermatol. 2005; 153:331-5.

22. Kikuchi Y, Fann T, Kaplan A. Antithyroid antibodies in chronic urticaria and angioedema. J Allergy Clin Immunol. 2003;112:218.

23. Altrichter S, Peter HJ, Pisarevskaja D, Metz M, Martus P, Maurer M. IgE mediated autoallergy against thyroid peroxidase-a novel pathomechanism of chronic spontaneous urticaria? PLoS One. 2011;6:147-54.

24. - Maurer M, Altrichter S, Bieber T, et al. Efficacy and safety of omalizumab in patients with chronic urticaria who exhibit IgE against thyroperoxidase. J Allergy Clin Immunol. 2011;128:202-9. This study indicates that omalizumab is an effective treatment option for patients with $C U$ with IgE autoantibodies against thyroperoxidase who are refractory to conventional treatment.

25. - Bossi F, Frossi B, Radillo O, Cugno M, Tedeschi A, Riboldi P, et al. Mast cells are critically involved in serum-mediated vascular leakage in chronic urticaria beyond high-affinity $\operatorname{IgE}$ receptor stimulation. Allergy. 2011;66:1538-45. The study shows that $C U$ sera are able to degranulate mast cells through an $\operatorname{IgE} E$ - and $\operatorname{Ig} G$ independent mechanism.

26. Antiga E, Volpi W, Del Bianco E, Fabbri P, Caproni M. Plasma levels of metalloproteinase- 9 are elevated in patients with chronic autoimmune urticaria. Br J Dermatol. 2009;161:712-4.

27. Altrichter S, Boodstein N, Maurer M. Matrix metalloproteinase-9: a novel biomarker for monitoring disease activity in patients with chronic urticaria patients? Allergy. 2009;64:652-6.
28. - Tedeschi A, Asero R, Lorini M, Marzano AV, Cugno M. Plasma levels of matrix metalloproteinase-9 in chronic urticaria patients correlate with disease severity and C-reactive protein but not with circulating histamine-releasing factors. Clin Exp Allergy. 2010;40:875-81. The results of this study indicate that in $C U$ there is an ongoing inflammatory process independent of the presence of circulating histamine-releasing factors.

29. Kanbe N, Tanaka A, Kanbe M, Itakura A, Kurosawa M, Matsuda H. Human mast cells produce matrix metalloproteinase 9. Eur J Immunol. 1999;29:2645-9.

30. Ram M, Sherer Y, Shoenfeld Y. Matrix metalloproteinase-9 and autoimmune diseases. J Clin Immunol. 2006;26:299-307.

31. Marzano AV, Cugno M, Trevisan V, et al. Role of inflammatory cells, cytokines and matrix metalloproteinases in neutrophil mediated skin diseases. Clin Exp Immunol. 2010;162:100-7.

32. Asero R, Tedeschi A, Riboldi P, Cugno M. Plasma of patients with chronic urticaria shows signs of thrombin generation, and its intradermal injection causes wheal-and-flare reactions much more frequently than autologous serum. J Allergy Clin Immunol. 2006;117:1113-7.

33. Goldsack NR, Chambers RC, Dabbagh K, Laurent GJ. Thrombin. Int J Biochem Cell Biol. 1998;30:641-9.

34. Schaeffer RC, Gong F, Bitrick MS, Smith TL. Thrombin and bradykinin initiate discrete endothelial solute permeability mechanisms. Am J Physiol. 1993;264:1798-09.

35. Cirino G, Cicala C, Bucci MR, Sorrentino L, Maranganore JM, Stone SR. Thrombin functions as an inflammatory mediator through activation of its receptors. J Exp Med. 1996;183:821-7.

36. Vliagoftis $\mathrm{H}$. Thrombin induces mast cell adhesion to fibronectin: evidence for the involvement of protease-activated receptor-1. J Immunol. 2002;169:4551-8.

37. Razin E, Marx G. Thrombin-induced degranulation of cultured bone marrow-derived mast cells. J Immunol. 1984;133:3282-5.

38. Asero R, Tedeschi A, Coppola R, Griffini S, Paparella P, Riboldi P, et al. Activation of the tissue pathway of blood coagulation in patients with chronic urticaria. J Allergy Clin Immunol. 2009;119:705-10.

39. Asero R, Tedeschi A, Riboldi P, Griffini S, Bonanni E, Cugno M. Severe chronic urticaria is associated with elevated plasma levels of D-dimer. Allergy. 2008;63:176-80.

40. • Cugno M, Marzano AV, Tedeschi A, Fanoni D, Venegoni L, Asero R. Expression of tissue factor by eosinophils in patients with chronic urticaria. Int Arch Allergy Immunol. 2009;148:170-4. The study demonstrated that eosinophils are the main source of tissue factor in CU lesional skin providing the rationale for new therapeutic strategies.

41. Moosbauer C, Morgenstern E, Cuvelier SL, Manukyan D, Bidzhekov $\mathrm{K}$, Albrecht S, et al. Eosinophils are a major intravascular location for tissue factor storage and exposure. Blood. 2007;109:995-02.

42. Nobe K, Sone T, Paul RJ, Honda K. Thrombin-induced force development in vascular endothelial cells: contribution to alteration of permeability mediated by calcium-dependent andindependent pathways. J Pharmacol Sci. 2005;99:252-6.

43. Wang F, Tang H, Xu J, Kang K. Activation of the blood coagulation cascade is involved in patients with chronic urticaria. J Allergy Clin Immunol. 2009;123:972-3.

44. Fujii K, Usuki A, Kan-No Y, Ohgou N. Elevation of circulating thrombin-antithrombin III complex and fibrin degradation products in urticaria. A laboratory finding unrelated to intravascular coagulopathy. J Dermatol. 2009;35:308-10.

45. Khalaf AT, Liu XM, Sheng WX, Tan JQ, Abdalla AN. Efficacy and safety of desloratadine combined with dipyridamole in the treatment of chronic urticaria. J Eur Acad Dermatol Venereol. 2008;22:487-92.

46. Takeda T, Sakurai Y, Takahagi S, et al. Increase of coagulation potential in chronic spontaneous urticaria. Allergy. 2011;66:428-33.

47. Yancey KB. The pathophysiology of autoimmune blistering diseases. J Clin Invest. 2005;115:825-8. 
48. Marzano AV, Tedeschi A, Fanoni D, et al. Activation of blood coagulation in bullous pemphigoid: role of eosinophils, and local and systemic implications. Br J Dermatol. 2009;160:266-72.

49. Marzano AV, Tedeschi A, Spinelli D, Fanoni D, Crosti C, Cugno M. Coagulation activation in autoimmune bullous disease. Clin Exp Immunol. 2009;158:31-6.

50. Cugno M, Tedeschi A, Asero R, Meroni PL, Marzano AV. Skin autoimmunity and blood coagulation. Autoimmunity. 2010;43:189-94.

51. Marzano AV, Tedeschi A, Berti E, Fanoni D, Crosti C, Cugno M. Activation of coagulation in bullous pemphigoid and other eosinophilrelated inflammatory skin diseases. Clin Exp Immunol. 2011;165:44 50 .

52. Marzano AV, Tedeschi A, Polloni I, Crosti C, Cugno M. Interactions between inflammation and coagulation in autoimmune and immunemediated skin diseases. Curr Vasc Pharmacol. 2012;10:647-52.

53. . Cugno M, Asero R, Tedeschi A, Lazzari R, Marzano AV. Inflammation and coagulation in urticaria and angioedema. Curr Vasc Pharmacol. 2012;10:653-8. This review summarizes all the studies that have demonstrated the involvement of the coagulation cascade in urticaria and angioedema, providing the rationale for the clinical evaluation of anticoagulant and antifibrinolytic drugs in these diseases.

54. Vaswani SK, Plack RH, Norman PS. Acute severe urticaria and angioedema leading to myocardial infarction. Ann Allergy Asthma Immunol. 1996;77:101-4.

55. Pontillo D, Capezzuto A, Castellani R. Acute generalized urticaria leading to acute myocardial infarction. Angiology. 2000;51:89-90.

56. Yaegashi T, Nakamura Y, Sakagami S, Saeki T, Omi W, Ikeda K. Acute myocardial infarction following food-dependent exerciseinduced anaphylaxis. Intern Med. 2011;50:451-4.

57. Connor S, Child N, Burdon-Jones D, Connor A. Cardiac arrest secondary to type 2 kounis syndrome resulting from urticaria and angioedema. Emerg Med J. 2010;27:568-9.

58. Meyer-De Schmid JJ, Neuman A. Treatment of chronic urticaria with heparin. Bull Soc Fr Dermatol Syphiligr. 1952;59:286-7.

59. Chua SL, Gibbs S. Chronic urticaria responding to subcutaneous heparin sodium. Br J Dermatol. 2005;153:216-7.

60. Parslew R, Pryce D, Ashworth J, Friedmann PS. Warfarin treatment of chronic idiopathic urticaria and angio-oedema. Clin Exp Allergy. 2000;30:1161-5.

61. Mahesh PA, Pudupakkam VK, Holla AD, Dande T. Effect of warfarin on chronic idiopathic urticaria. Indian J Dermatol Venereol Leprol. 2009;75:187-9.
62. Cicardi M, Bergamaschini L, Zingale LC, Gioffré D, Agostoni A. Idiopathic non-histaminergic angioedema. Am J Med. 1999;106:650 4.

63. Cugno M, Cicardi M, Bottasso B, Coppola R, Paonessa R, Mannucci PM, et al. Activation of the coagulation cascade in C1-inhibitor deficiencies. Blood. 1997;89:3213-8.

64. Cugno M, Zanichelli A, Bellatorre AG, Griffini S, Cicardi M. Plasma biomarkers of acute attacks in patients with angioedema due to C1-inhibitor deficiency. Allergy. 2009;64:254-7.

65. Tant D. Tranexamic acid in chronic urticaria. Br Med J. 1979;1:266.

66. Laurberg G. Tranexamic acid (cyklokapron) in chronic urticaria: a double-blind study. Acta Derm Venereol. 1977;57:369-70.

67. Asero R, Tedeschi A, Cugno M. Heparin and tranexamic acid therapy may be effective in treatment-resistant chronic urticaria with elevated d-dimer: a pilot study. Int Arch Allergy Immunol. 2010;152:384-9.

68. Fradin MS, Ellis CN, Voorhees JJ. Chronic urticaria and treatment options. J Am Acad Dermatol. 1991;25:1065-7.

69. Barlow RJ, Kozba BA, Greaves MW. Treatment of severe chronic urticaria with cyclosporine A. Eur J Dermatol. 1993;3:273-5.

70. Kessel A, Toubi E. Cyclosporine-a in severe chronic urticaria: the option for long-term therapy. Allergy. 2010;65:1478-82.

71. - Zuberbier T, Asero R, Bindslev-Jensen C, Walter Canonica G, Church MK, Giménez-Arnau AM et al. EAACI/GA(2)LEN/EDF/ WAO guideline: management of urticaria. Allergy. 2009;64:142743. This guideline is the result of a consensus reached during the discussion of a panel of international experts on the management of urticaria.

72. Grattan CEH, Francis DM, Slater NGP. Randomised double-blind study of cyclosporine in chronic idiopathic urticaria. Br J Dermatol. 2000;143:365-72.

73. Vena G, Cassano N, Colombo D, Peruzzi E, Pigatto P. Cyclosporine in chronic idiopathic urticaria: a double-blind, randomized, placebo-controlled trial. J Am Acad Dermatol. 2006;55:705-9.

74. Kahan BD. Cyclosporine. N Engl J Med. 1989;321:1725-38.

75. Holschermman H, Kohl O, Maus U, Durfeld F, Bierhaus A, Nawroth $\mathrm{PP}$, et al. Cyclosporin a inhibits Monocyte tissue factor activation in cardiac transplant recipients. Circulation. 1997;96:4232-8.

76. Holschermann H, Durfeld F, Maus U, Bierhaus A, Heidinger K, Lohmeyer J, et al. Cyclosporine A inhibits tissue factor expression in monocytes/macrophages. Blood. 1996;88:3837-45. 